\title{
Effect of Particle Size and Concentration of Flyash on Properties of Polyester Thermoplastic Elastomer Composites
}

\author{
M.S. Sreekanth ${ }^{1}$, V.A. Bambole ${ }^{2}$, S.T. Mhaske ${ }^{1}$, P.A. Mahanwar ${ }^{1 *}$ \\ 1. Department Polymer Engineering \& Technology \\ 2. Department of Applied Physics \\ Institute of Chemical Technology, Matunga, Mumbai-400019, India \\ *E-mail: pmahanwar@yahoo.com, ${ }^{1}$ Email: sreekanth.sms@gmail.com
}

\begin{abstract}
The performance of filled polymers is generally determined on the basis of the interface attraction of filler and polymers. Particulate filled polymer composites are becoming attractive because of their wide applications and low cost. In this study the effects of flyash with three varying particle size and filler concentrations (viz. 5 to 40 weight \%) on the mechanical, thermal, electrical, rheological and morphological properties of polyester thermoplastic elastomer $\left(\right.$ Hytrel $\left.^{\circledR}\right)$ was investigated. Composites of polyester thermoplastic elastomer with varying concentrations of flyash were prepared by twin screw extrusion. Mechanical properties such as flexural strength and modulus increases with filler loading, where as tensile strength is found to be decrease with increase in flyash loading. Dielectric strength of composites also increases with flyash loading. Morphological studies revealed that there is good dispersion of filler in the polymer matrix. Thermal properties were found to be improved with flyash addition. Further, it was observed that the mechanical (flexural), thermal as well as electrical properties of composites improved with decrease in particle size of filler.
\end{abstract}

Key Words: Particulate composites, thermoplastic elastomers, hytrel, flyash.

\section{INTRODUCTION}

Fillers are used along with various commodity as well as engineering polymers to improve the properties [1] and reduce the cost. Incorporating inorganic mineral fillers into plastic resin improves various physical properties of the materials such as mechanical strength, modulus etc. In general the mechanical properties [2] of particulate filled polymer composites depend strongly 
on size, shape and distribution of filler particles in the polymer matrix and extend of interfacial adhesion between filler and matrix.

Polyester thermoplastic elastomer $\left(\right.$ Hytrel $\left.^{\circledR}\right)$ is an important engineering thermoplastic elastomer, combines the physical properties of elastomer with the excellent processing characteristics of thermoplastic. Polyester thermoplastic elastomer [3] consisting of poly(butylene terephthalate) (PBT), as hard segments and poly(tetramethylene ether glycol terephthalate) as soft segments. The basic structure of polyester thermoplastic elastomer is shown in scheme 1. Polyester thermoplastic elastomer shows outstanding mechanical properties $[4,5]$ at temperatures up to $130^{\circ} \mathrm{C}$ coupled with very good low temperature flexibility. It shows good resistance to tear, impact, abrasion and creep and excellent oil, hydraulic fluids and grease resistance. In order to improve thermal, mechanical and electrical properties of polyester thermoplastic elastomer, particulate fillers such as aluminatrihydrate, montmorillonite, clays, talc, mica, silica, flyash, wollastonite, kaolin etc are incorporated [6]. Flyash had been one of the widely studied filler due to its unique set of properties $[2,7]$.

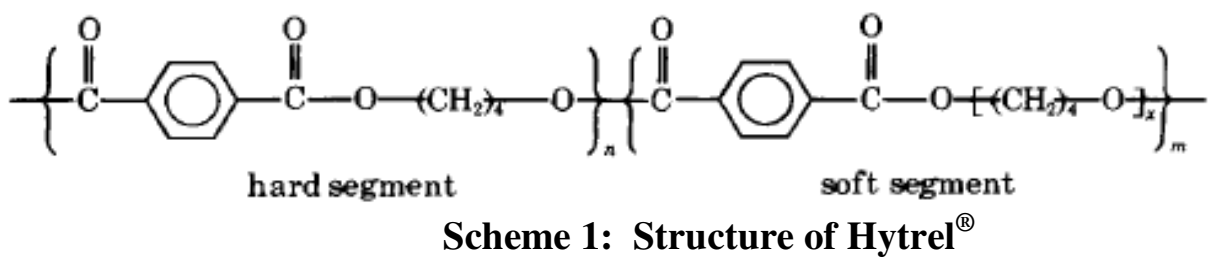

In this investigation we studied the effect of flyash with three varying particle sizes and concentration on properties Hytrel ${ }^{\circledR}$. Recently many investigators studied the effect of flyash on properties of thermoplastics and thermosets [8-13]. Flyash is the finely divided mineral residue resulting from the burning of pulverised coal in thermal power stations. Flyash has been used in industry because of such advantages as low density, low cost, strong filling ability, smooth spherical surface, small and well distributed internal stress in the products and good processability of the filled materials. Flyash provides cost effective improvements in the critical properties for a wide range of polymer composites. Polyester thermoplastic elastomer composites are mainly used in a wide variety of automotive parts such as gears and sprockets [3]. It is also used in high strength industrial hoses and tubing [14, 15] and also in vibration damping applications.

\section{EXPERIMENTAL}

\subsection{Materials}

The matrix polyester thermoplastic elastomer with $1.22 \mathrm{~g} / \mathrm{cc}$ density was procured from Rupal Plastics Ltd (Mumbai, India). The filler flyash of three different particle sizes $(25-45 \mu \mathrm{m}, 90$ $105 \mu \mathrm{m} \& 150-180 \mu \mathrm{m}$ ) was obtained from Pozocrete Minerals (Mumbai, India). The detail list of materials used is given in Table 1 below. 
Table 1. Materials used.

\begin{tabular}{|c|c|c|c|}
\hline \multirow{2}{*}{ Materials used } & Function & Grade & Suppliers \\
\hline \multirow{2}{*}{ Polyester TPE } & \multirow{2}{*}{ Polymer matrix } & Hytrel 6356 & $\begin{array}{c}\text { M/S Rupal Plastics } \\
\text { Ltd, Mumbai, India }\end{array}$ \\
\hline \multirow{2}{*}{ Flyash } & \multirow{2}{*}{ Filler } & $\begin{array}{c}\text { Pozocrete } 80 \\
(25-45 \mu \mathrm{m})\end{array}$ & \\
& & $\begin{array}{c}\text { Pozocrete80 } \\
(90-105 \mu \mathrm{m})\end{array}$ & $\begin{array}{c}\text { Novelty Business } \\
\text { Corporation } \\
\end{array}$ \\
\cline { 3 - 3 } & & $\begin{array}{c}\text { Pozocrete } 50 \\
(150-180 \mu \mathrm{m})\end{array}$ & \\
\cline { 3 - 3 } & & & \\
\hline
\end{tabular}

\subsection{Compounding}

The matrix and filler was predried prior to the compounding. Polyester thermoplastic elastomer and flyash were dried at $80^{\circ} \mathrm{C}$ for 6 hours in an air circulated oven and then both of them are dry blended to a uniform physical dispersion of polymer and filler. The following composition of filler (viz. 5 to 40 weights \%) shown in the table was mixed and extruded in a co-rotating twin extruder (APV Baker Ltd. England, Model: MP19PC). The L/D ratio of the screw is 25:1. Mixing speed of $60 \mathrm{rpm}$ was maintained for all the compositions. The extrudates from the die were quenched in a tank at $20-25{ }^{\circ} \mathrm{C}$ and then palletized. For the melt blending the temperature profile of the extrusion were as follows, Zone 1: $\left(120{ }^{0} \mathrm{C}\right)$, Zone $2:\left(180{ }^{0} \mathrm{C}\right)$, Zone $3:\left(210{ }^{0} \mathrm{C}\right)$, Zone 4: $\left(225{ }^{\circ} \mathrm{C}\right)$ and Die $\left(240{ }^{\circ} \mathrm{C}\right)$. The extrudates were pelletised in Boolani's pelletizing machine. The speed of the pelletizer was maintained between the ranges of 2-3 rpm.

\subsection{Injection Molding}

The granules of the extrudates were predried in an air circulated oven at $80^{\circ} \mathrm{C}$ for 8 hours and injection molded in a microprocessor based Boolani's injection moulding machine fitted with a master mould containing the cavity for tensile strength, flexural and impact specimens. After its ejection from the mould, specimens were cooled in ice-water. Processing parameters are Zone 1: $\left(150^{\circ} \mathrm{C}\right)$, Zone $2:\left(225^{\circ} \mathrm{C}\right)$, Zone $3:\left(245^{\circ} \mathrm{C}\right)$.

\section{CHARACTERIZATION}

\subsection{Mechanical Properties}

Tensile strength as per ASTM D638 M91 was evaluated using Universal Testing Machine LR50K from Lloyd instruments Ltd.,U.K at a crosshead speed of $50 \mathrm{~mm} / \mathrm{min}$. Flexural properties according to ASTM D790 were tested using LR 50K from Lloyd instruments Ltd., U.K. Izod impact test were carried out using an Avery Denison impact tester (ASTM D256-92). A 5.0 J 
energy hammer was used and the striking velocity was $3.46 \mathrm{~m} / \mathrm{sec}$. For Izod impact test specimens the notch was cut using a motorized notch- cutting machine (Rayran U.K). The impact strength is expressed in $\mathrm{J} / \mathrm{m}^{2}$.

\subsection{Electrical Properties}

The Dielectric Strength, according to ASTM D 149, was measured using Zaran Instruments (India) with a $2 \mathrm{~mm}$ thick composite disc. The voltage was increased slowly and the voltage at which the current penetrated the sample was noted. The configurations of the instruments were: input: $240 \mathrm{~V}, 50 \mathrm{~Hz}, 1 \mathrm{PH}$; output: $0-50 \mathrm{kV}$; capacity: $100 \mathrm{~mA}$; rating: $15 \mathrm{~min}$.

\subsection{Thermal Properties}

DSC is used to study the thermal properties of the composites. DSC measurements were performed using TA Q100 analyzer (TA Instruments, U.S.). The weight of sample was between 6 to $9 \mathrm{mg}$ in a standard aluminium pan.

\subsection{Rheological Properties}

The melt rheology of the polymer and the composites were studied using a rotational rheometer (Haake RT 10, Germany), employing a parallel plate assembly, diameter $35 \mathrm{~mm}$, at $245^{\circ} \mathrm{C}$. The samples were predried before analysis. The shear rate range was varied from $1-100 \mathrm{~s}^{-1}$. Melt viscosity, $\eta$ (Pa s) as a function of shear rate, $\gamma(1 / \mathrm{s})$ was recorded.

\subsection{Morphological Properties}

SEM is used to study the morphology of the composites. SEM studies of fractured impact samples were carried out on a Cameca SU-SEM probe. The accelerated voltage used was $15 \mathrm{kV}$. Samples were sputter-coated with gold to increase surface conductivity. The digitized images were recorded.

\section{RESULTS AND DISCUSSION}

\subsection{Tensile Properties}

Fig. 1 shows the variation of tensile strength as a function of flyash in wt $\%$. Tensile strength of composites was found to decreases with the addition of filler. The rate of decrease of tensile strength is higher in the case of larger particle size of flyash. It is observed that flyash with smaller particles showed higher value of tensile strength. The percentage elongation at break is also decreases [10] on addition on filler as shown in Fig. 2. This is due to the interference of filler in the mobility or deformability of the matrix. This interference is created through the physical interaction and immobilisation of the polymer matrix by the presence of mechanical restraints, there by reducing the elongation at break. Flyash with smaller particle size show higher values of elongation at break. 


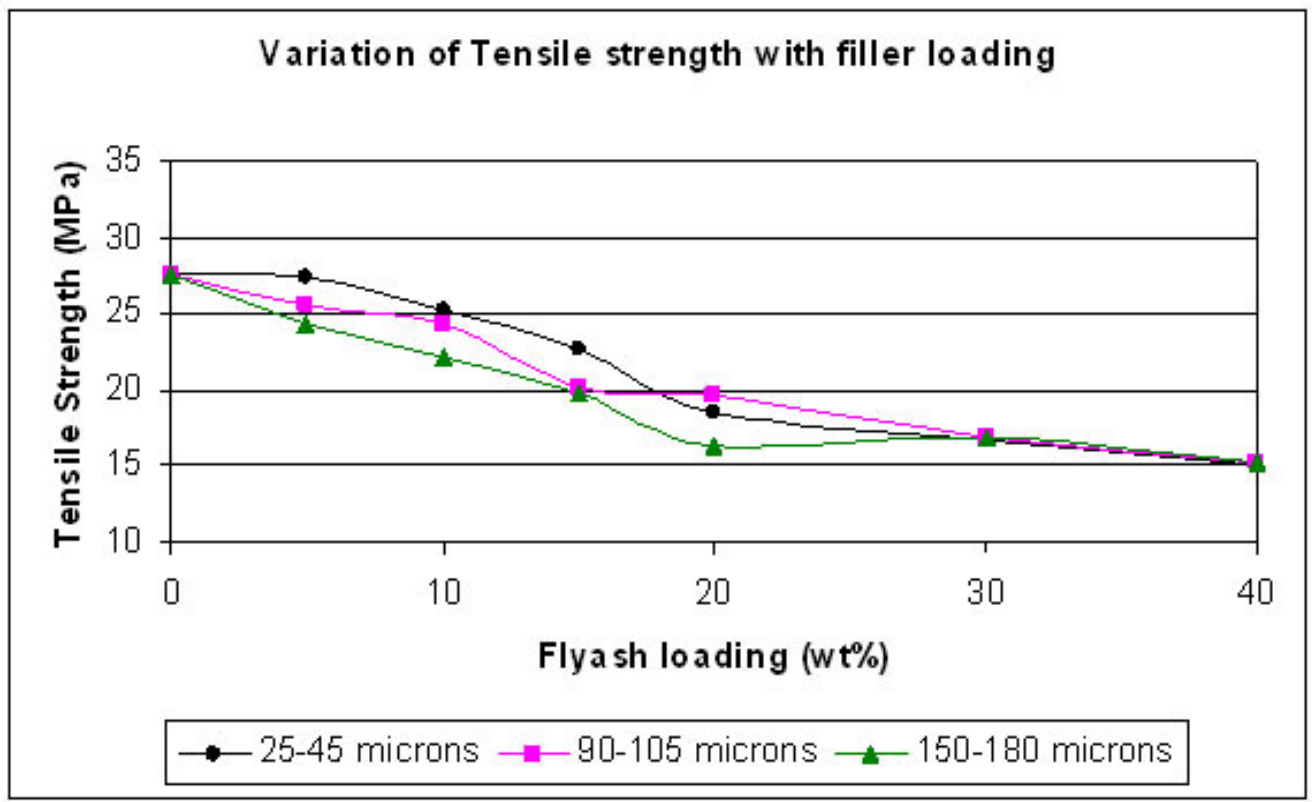

Figure 1. Variation of Tensile Strength of Polyester Thermoplastic Elastomer with Filler Concentration.

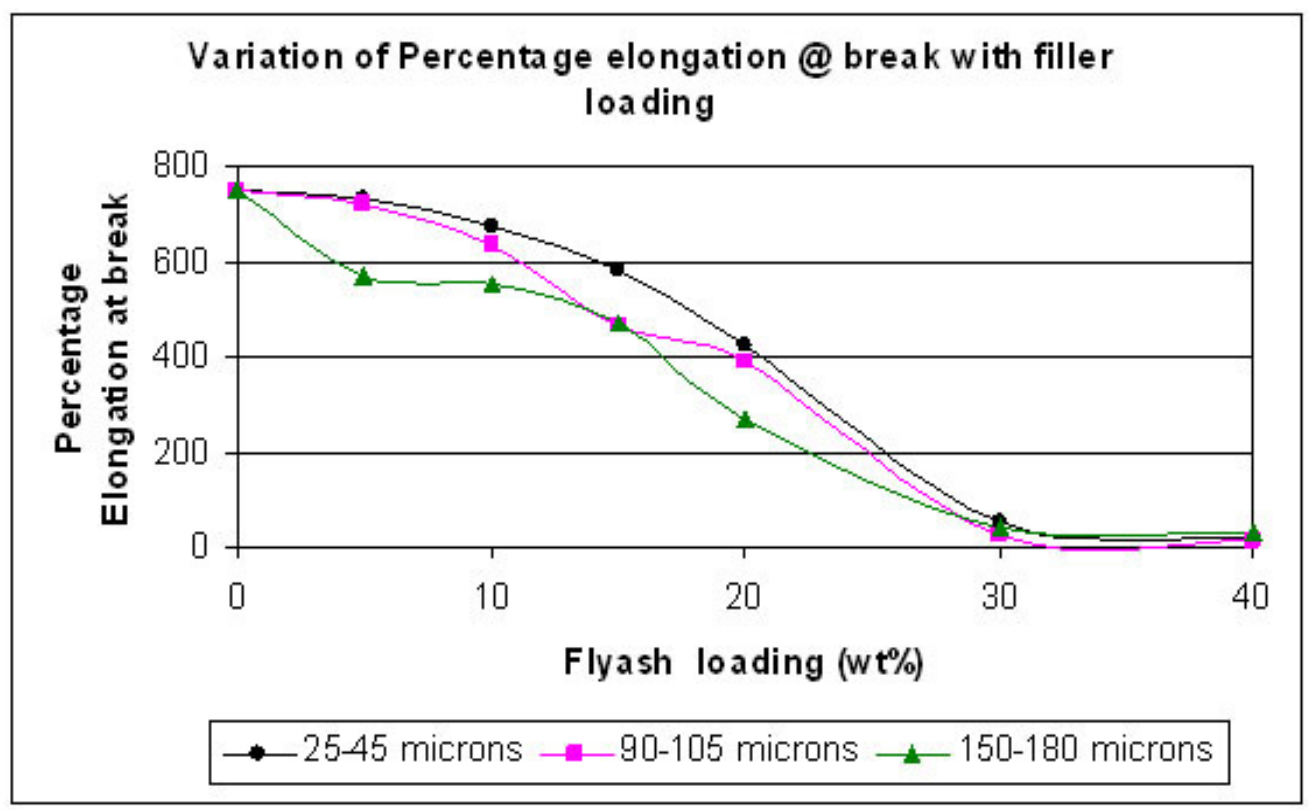

Figure 2. Variation of Elongation at break of Polyester Thermoplastic Elastomer with Filler Concentration.

\subsection{Flexural Properties}

The variation of flexural strength with filler addition is shown in Fig. 3. The flexural strength of composites increases with increase in concentration of flyash. Composites with flyash at smaller particle size show higher value of flexural strength. The increment in flexural strength is due to 
the better increased surface area of filler in the matrix. It is worth pointing out that the total area for deformation stress also has an important role to play. Flexural modulus [16] as shown in Fig. 4 is found to increase with increase in concentration of flyash. The rate of increase of flexural modulus is higher in the case of smaller particle size of flyash. Composites with flyash at smaller particle size show consistant and better values of flexural properties.

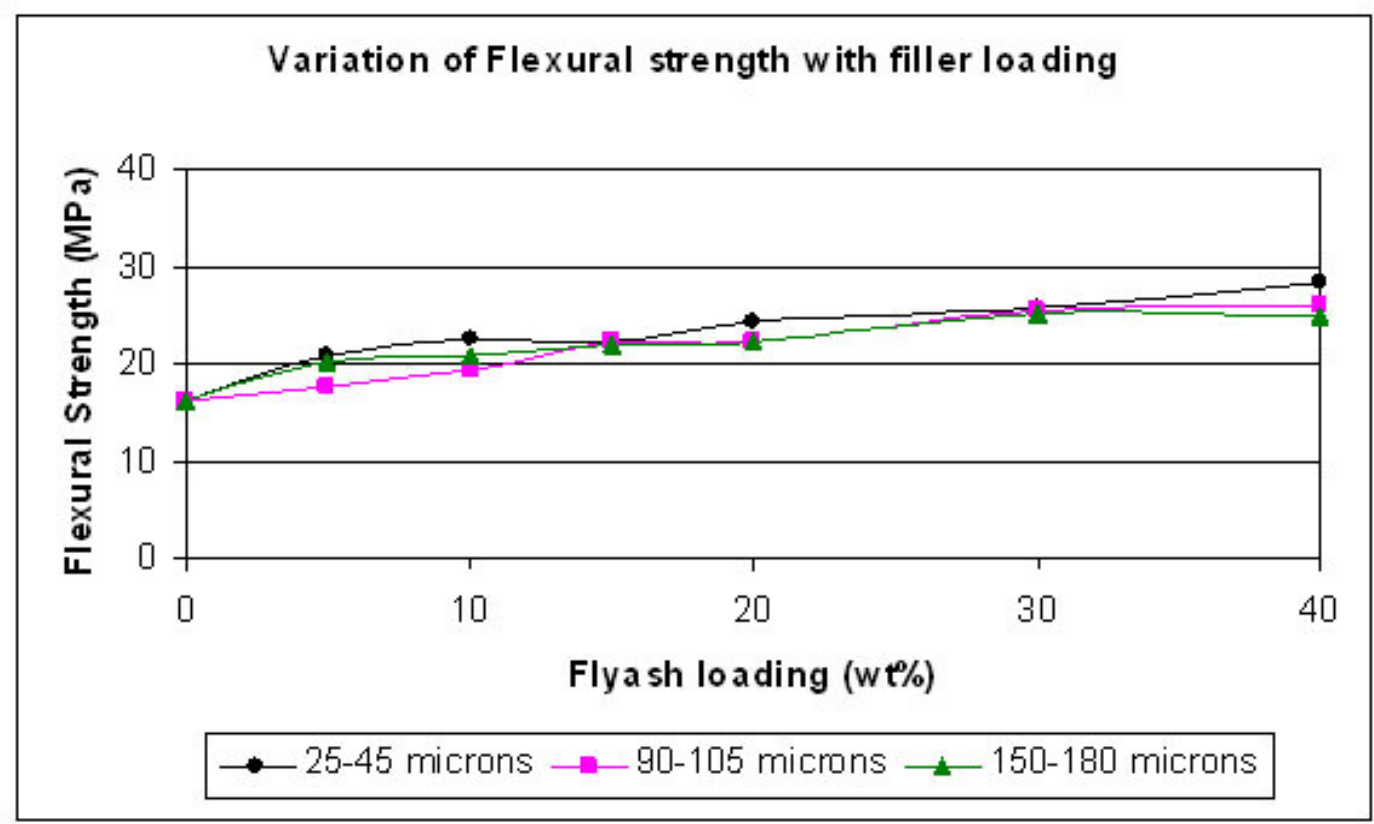

Figure 3. Variation of Flexural strength of Polyester Thermoplastic Elastomer with Filler Concentration.

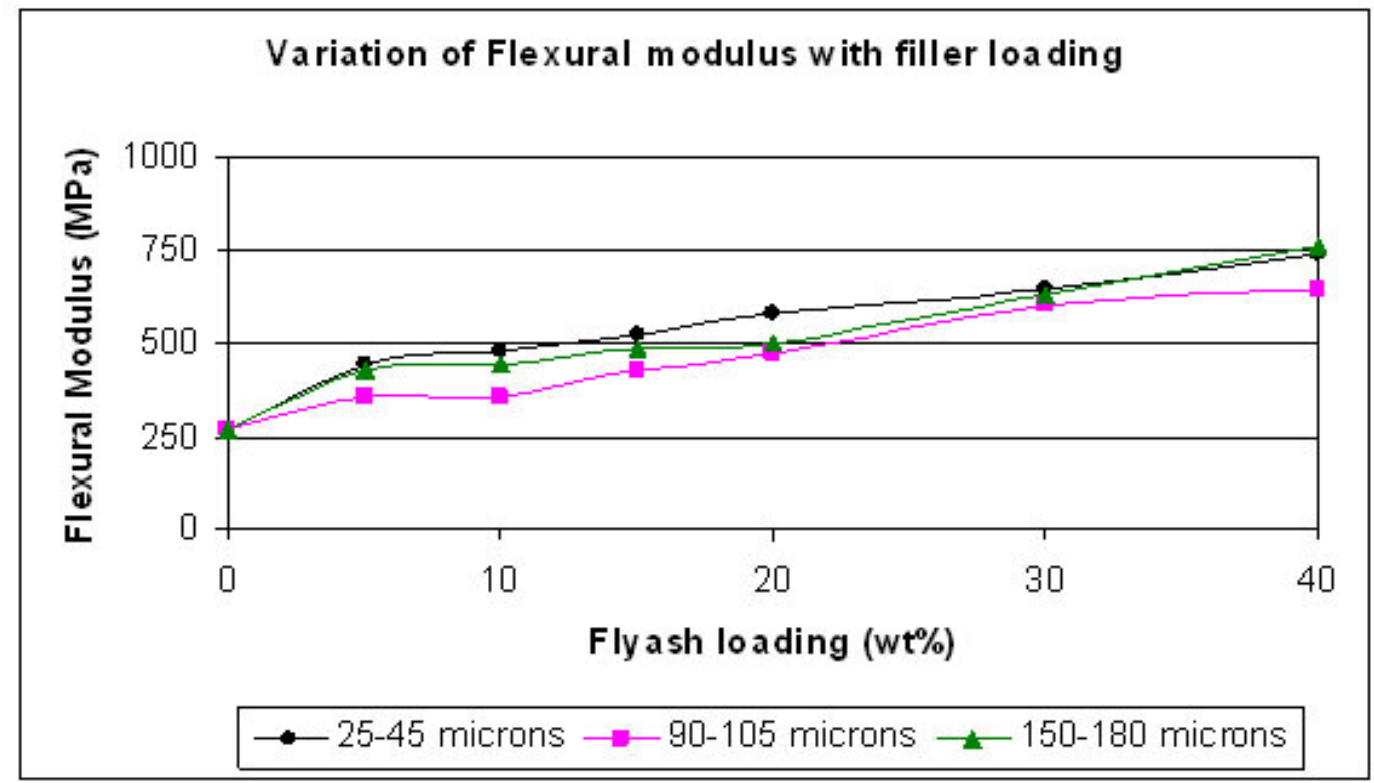

Figure 4. Variation of Flexural modulus of Polyester Thermoplastic Elastomer with Filler Concentration. 


\subsection{Impact Strength}

Fig. 5 illustrates the variation of impact strength with filler loading. It is clear from the figure that the impact strength decreases with filler addition. This is mainly due to the reduction of elasticity [10] of material due to filler addition and there by reducing the deformability of matrix. An increase in concentration of filler reduces the ability of matrix to absorb energy and there by reducing the toughness, so impact strength decreases. It is observed that the flyash with smaller particle size showing higher increment of impact strength. The rate of decrease of impact strength is higher in the case of smaller particle size of flyash.

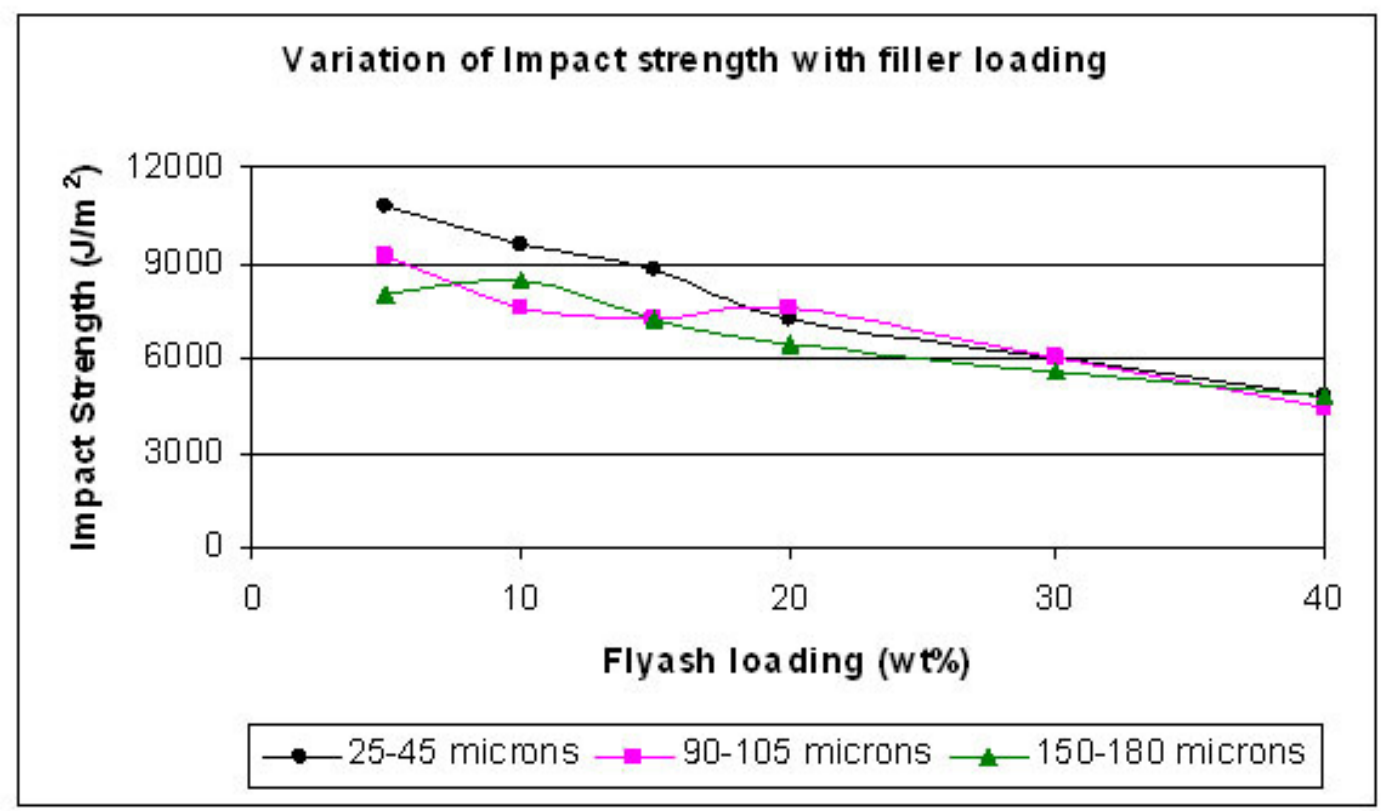

Figure 5. Variation of Impact Strength of Polyester Thermoplastic Elastomer with Filler Concentration.

\subsection{Dielectric Strength}

It is clear from Fig. 6 that the dielectric strength increased with the increase in filler concentration and attained maxima. At higher filler loading the dielectric strength values remained almost constants with the increase in filler. This trend in variation of dielectric strength in flyash is attributed to the total surface area available from the filler as well as its continuity. The dielectric strength is higher for smaller particle size of flyash. 


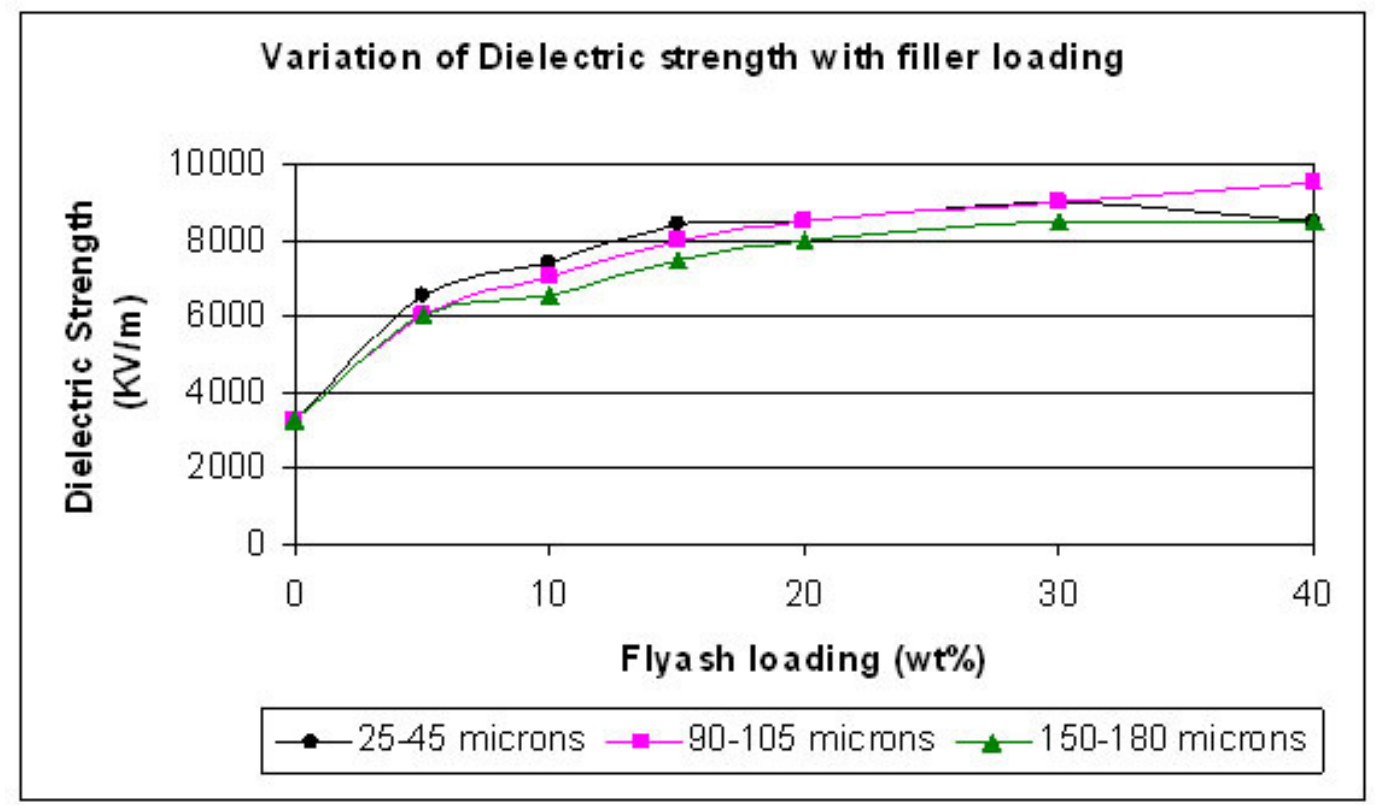

Figure 6. Variation of Dielectric Strength of Polyester Thermoplastic Elastomer with Filler Concentration.

\subsection{Thermal Properties}

The melting and the crystallisation temperature of the composites were studied by using DSC. Fig. 7 shows the variation of melting temperature with filler addition. The polymer matrix showed a melting temperature around $211.95^{\circ} \mathrm{C}$. Addition of filler increases the melting point of composites up to $3{ }^{\circ} \mathrm{C}$ manifesting the fact that the addition of filler improves the thermal stability of composites. Fig. 8 shows the variation of crystallisation temperature with filler addition. The matrix polymer shows a crystallisation temperature around $170.05{ }^{\circ} \mathrm{C}$. Further, flyash acts as a nucleating agent manifesting in higher crystallisation temperature in the composites. The crystallisation temperature is shifted right to around $8{ }^{\circ} \mathrm{C}$ with the addition of filler from 5 to $40 \mathrm{wt} \%$. The increment is due to the small and uniform crystallite size distribution. There is no significant variation of thermal properties with particle size of filler.

\subsection{Rheological Properties}

Fig. 9 illustrates the variation of shear viscosity at $245{ }^{0} \mathrm{C}$ (in Pascal sec) with filler concentration at a shear rate at $0.1 \mathrm{sec}^{-1}$. Increase in the viscosity may be attributed to the properties of the filler such as maximum packing fraction. The increase in viscosity [17] was due to the ability of fine particles of filler particle to form a tight packing network. Rate of increase in the viscosity depended upon the ratio $(\varnothing / \varnothing \mu)$, where $\varnothing=$ vol. fraction of the filler and $\varnothing \mu=$ Max. packing fraction. With an increase in filler content the viscosity of the component increased. Rheological study showed that smaller particle size of flyash giving higher value of viscosity. 


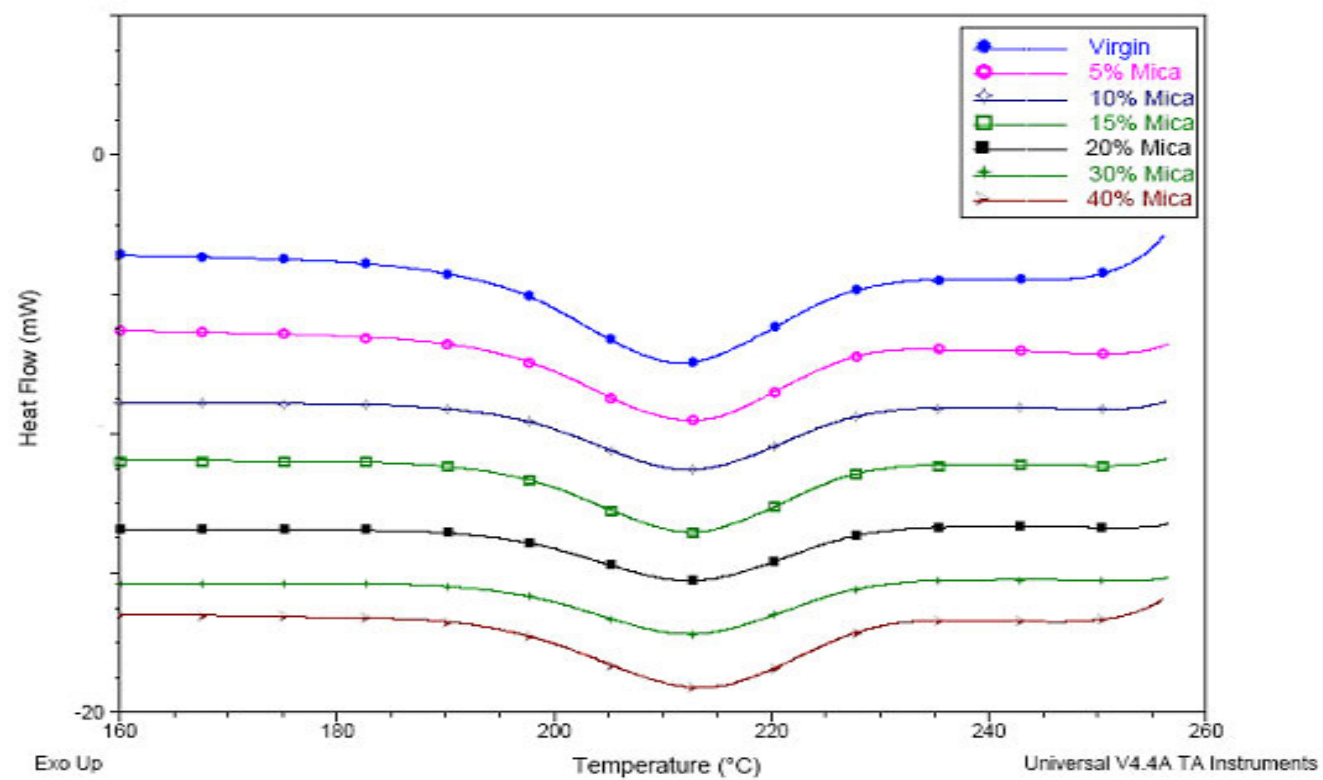

Figure 7. Variation of Melting Temperature of Polyester Thermoplastic Elastomer with Filler Concentration.

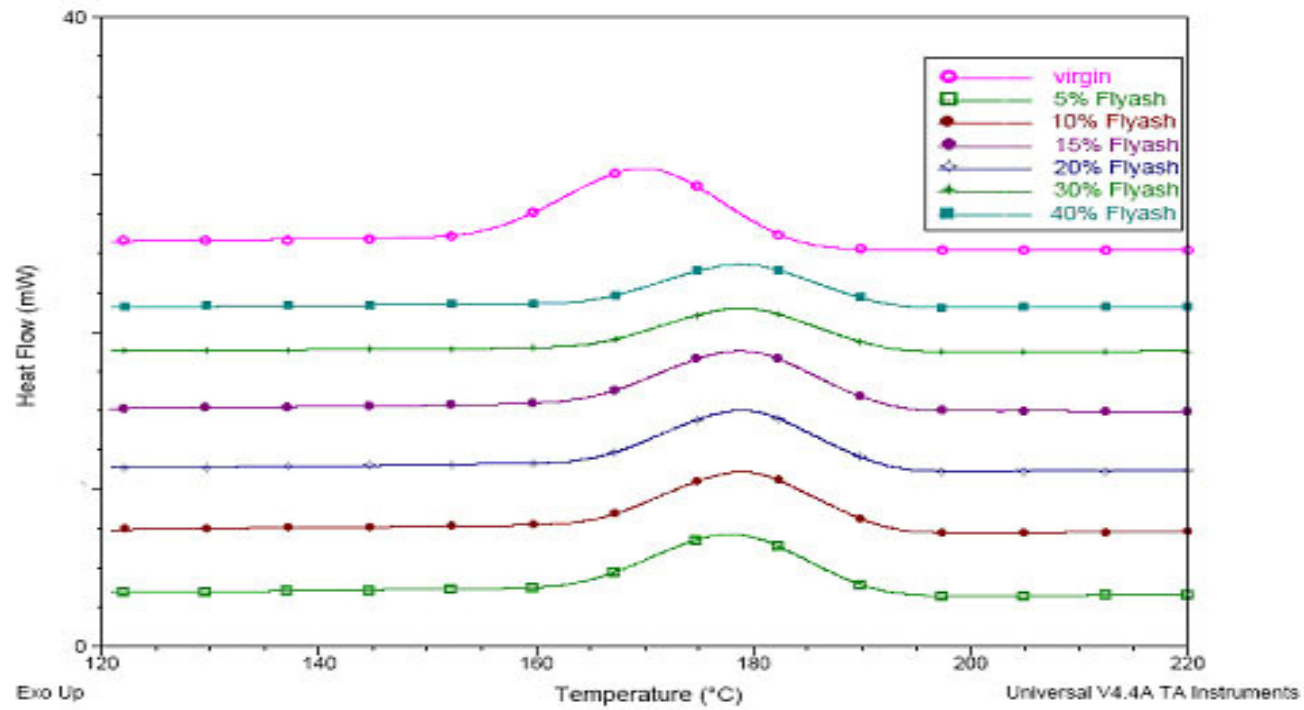

Figure 8. Variation of Crystallisation Temperature of Polyester Thermoplastic Elastomer with Filler Concentration. 


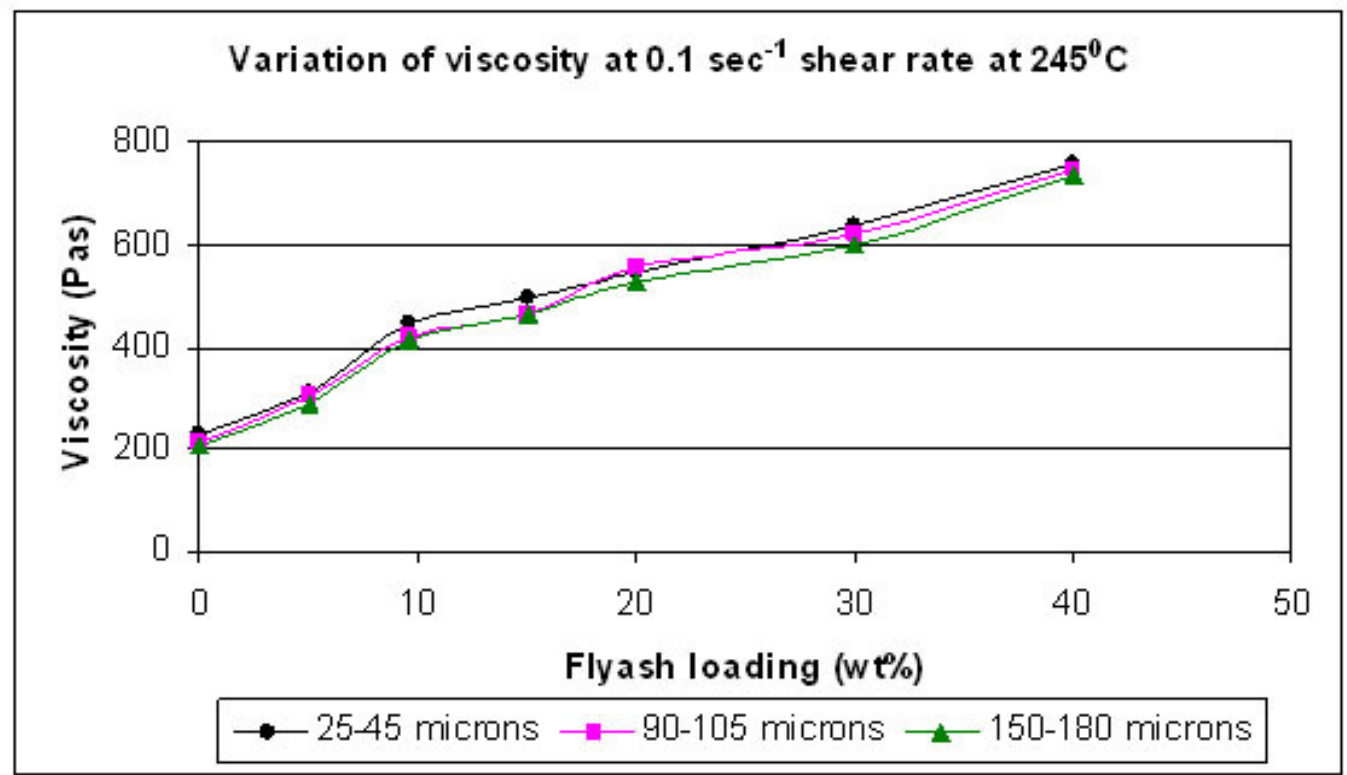

Figure 9. Variation of Shear Viscosity at 0.1 Shear rate at $245^{\circ} \mathrm{C}$ with filler loading.

\subsection{Morphological Properties}

SEM is used to study the morphology of composites. Fig. 10 shows the SEM micrographs of composites with $20 \%$ loadings of flyash. Morphological study shows that flyash having smooth spherical surface having more surface area for interaction. There is a good dispersion of filler particle in the polymer matrix. The interaction between the filler and the matrix is also good as shown in the SEM micrograph.

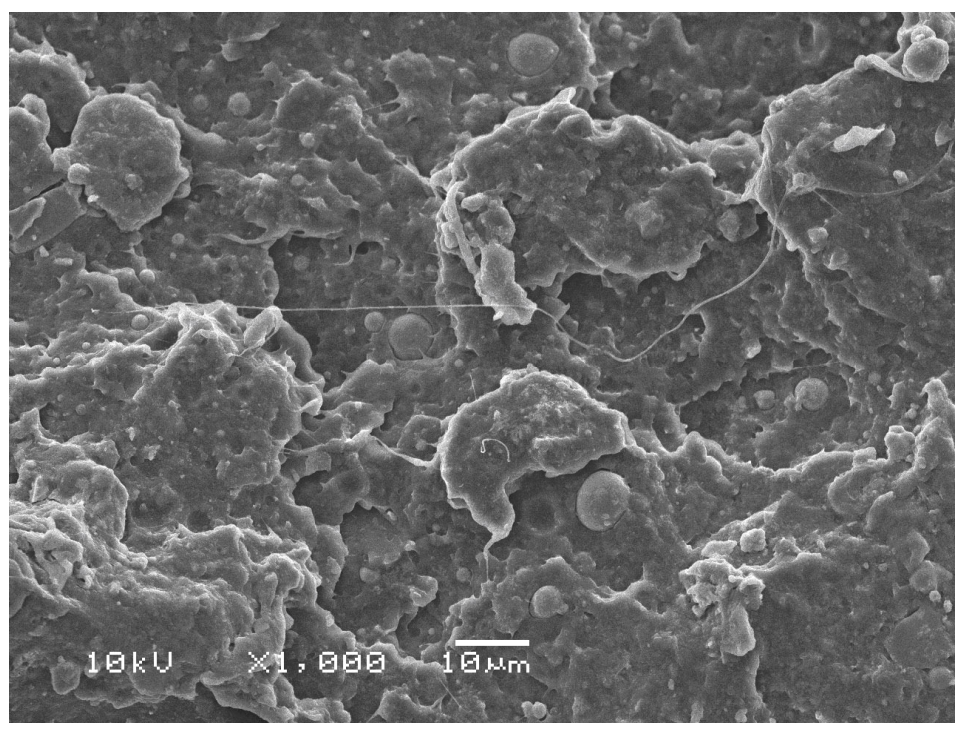

Figure10. SEM micrograph of Polyester Thermoplastic Elastomer with 10\% Flyash of 25-45 $\mu \mathrm{m}$ particle size. 


\section{CONCLUSION}

Inorganic fillers viz. flyash added to the polymer improved its rigidity, strength, and thermal stability, but dramatically decreased the elongation at break. There is a significant increment in the flexural strength and modulus with an increase in the filler concentration. The impact strength decreases with concentration of filler due to the reduction of elasticity of material due to filler addition and there by reducing the deformability of matrix. There is a significant increase in the dielectric strength with filler addition. Addition of flyash improved the thermal properties of the composites due to small and uniform crystallite size distribution. Morphological studies showed that there is a better dispersion of filler in the matrix. The mechanical properties of the composite were found to be a function of the particle size, aspect ratio, the dispersion, the particle orientation, the interfacial interaction between the minerals and the polymer matrix. Spherical shaped filler, such as flyash gave significant improvement in stiffness due to better surface area for interaction. It is concluded that composites with flyash at smaller particle size showed significant improvement in the overall (mechanical and electrical) properties of composites.

\section{REFERENCES}

1. Lowrence,E., Nielson., 1974, Particulate Composites, Mechanical properties of Polymers and Composites, Vol.2, ed.1, pp. 34-41, New York, Marcel Dekker.

2. Katz,H.S; J.V Milevski, 1978, "Handbook of Fillers and Reinforcements for Plastics", Vol.1, ed.1, pp. 301-316, New York, Van Notrand Reinhold.

3. Walker,B.M., 1979, Polyester Thermoplastic Elastomer, Handbook of Thermoplastic Elastomer, Vol.1, ed.1, pp. 103-118, New York, Litton Education Publishing.

4. Kaforglou,N.K., 1977, "Thermomechanical studies of semicrystalline polyether-ester copolymers" J.Appl Polym Sci, Vol. 21, pp. 543-554.

5. Nagai,Y., Ogawa,T., Zhen,LY., 1997, "Analysis of weathering of thermoplastic elastomers" Polym. Degrad. Stab, Vol.56, pp. 115-121.

6. Aso,O., Eguiazabal,J.I., Nazabal,J., 2007, “The influence of surface modification on the structure and properties of a nanosilica filled thermoplastic elastomer" Compo. Sci. Tech, Vol. 67, pp. 2854-2863.

7. George, W., 1999, Flyash, Mica, Handbook of Fillers, Vol. 1, ed. 2, pp. 32, Toronto, New York, Chem Tech Publishing.

8. Xuang,X., Hwang,J.Y., Gillis, J.M., 2003, "Processed Low NOx Fly Ash as a Filler in Plastics”, J.Min Mat.Char.\& Engg, Vol. 2, No.1, pp. 11-31.

9. Fen.Y.Y, Sheng.G.G, 2006, "Surface modification of purified fly ash and application in polymer", J. Hazard. Mater., vol. 133 pp. 276-282

10. Bose,S., Mahanwar,P.A., 2004, "Effect of flyash on the mechanical, thermal, dielectric, rheological and morphological properties of filled nylon-6" J.Min Mat .Char.\& Engg, Vol. 3, No.1, pp. 23-31.

11. Soyama.M, Inoue.K, 2007, "Flame retardancy of polycarbonate enhanced by adding fly ash" Polym. Adv. Tech. Vol. 18, pp. 386-391 
12. Menon.A.R.R, Sonia.T.A, 2006, "Studies on Fly-Ash-Filled Natural Rubber Modified with Cardanol Derivatives", J Appl. Polym. Sci., Vol. 102, pp.4801-4808.

13. Li.Y, White.D.J, 1998, "Composite material from fly ash and post-consumer PET", Resources Conservation and Recycling, Vol. 24, pp. 87-93

14. Joshi,A.D., 1993, “TPO vs PVC for automotive interior”, J. Coated Fabrics, Vol. 23, pp. 67- 73.

15. Parister,L.M., 1983, "Copolyester: The fuel resistant thermoplastic elastomer", J. Elastomer \& Plastics, Vol. 15, pp.146- 158.

16. He,D., Jiang,B., 1993, "The elastic modulus of filled polymer composites", J. Appl Polym Sci, Vol. 49, pp. 617-621.

17. Gahleitener,M., Neibl,W., 1994, "Correlation between Rheological and mechanical properties of mineral filled polypropylene composites", J. Appl Polym Sci, Vol. 53, pp. 283-289. 